\title{
GEODIVERSIDADE DOS DEPÓSITOS EÓLICOS E SUA AÇÃO PROTETORA A EROSÃO NA PRAIA DE ALMOFALA, ITAREMA - CEARÁ.
}

\author{
Ana Alexandre Santos Rodrigues ${ }^{(a)}$, Jáder Onofre de Morais ${ }^{(b)}$, Lidriana de Souza Pinheiro ${ }^{(c)}$ \\ (a) Centro de Ciências e Tecnologia, Universidade Estadual do Ceará, anageo.rodrigues@aluno.uece.br \\ (b) Centro de Ciências e Tecnologia, Universidade Estadual do Ceará, jaderrmorais@uece.br \\ (c) Instituto de Ciências do Mar, Universidade Federal do Ceará - Labomar (UFC), lidriana.lgco@ gmail.com
}

Eixo: GEODIVERSIDADE, GEOARQUEOLOGIA E PATRIMONIO NATURAL

\begin{abstract}
Resumo
A geodiversidade do litoral do Ceará é representada por morfologias diversas. Na valoração funcional da geodiversidade as dunas frontais e os eolianitos desempenham um papel fundamental na zona costeira de Almofala, sendo uma barreira protetora natural frente aos processos de erosão costeira. Foram selecionados seis pontos para ser realizada a identificação que os processos da dinâmica costeira exercem nessas formas. Através de registros fotográficos foram constatados que quatro pontos são referentes a dunas frontais, e os outros dois aos eolianitos. Ficou perceptível através desses registros fotográficos o espraiamento, que é um fator predominante na área, a sobrelavagem e o solapamento são localizados de forma pontual. A conservação desses geossítios costeiros é necessária, pois é perceptível a representatividade protetora frente à alta dinâmica do litoral deixando assim exposta a vulnerabilidade natural desse ambiente.
\end{abstract}

Palavras chave: Geodiversidade, dunas frontais, eolianitos, erosão costeira e valoração funcional.

\section{Introdução}

A zona costeira do estado do Ceará tem aproximadamente $573 \mathrm{~km}$ de extensão (Morais et.al, 2006). Os estudos da geodiversidade litorânea cearense iniciaram recentemente com trabalhos de Sousa (2007) no municipio de Icapuí com ênfase nas fálesias da região, dando destaque à propota de inserção do geoturismo na comunidade. Meira (2016) realizou estudos referentes ao patrimonio gelogico no parque nacional de Jericoacoara, propondo um roteiro geoturistico de fácil interpretação aos visitantes, contemplando a relevancia geologica - geomorfologica do parque.

A realização de trabalhos que abordem a geodiversidade na zona costeira torna-se relevante por conta da alta dinâmica que esse ambiente apresenta. Levando em consideração essa importância, o objetivo desse trabalho é demosntrar a função protetoras das feições dunas frontais e eolianitos, onde fora observado que são feições indicadoras de erosão costeira de acordo com a classificação do trabalho de Souza (2009), que dispõe sobre indicadores de erosão costeira, onde a erosão dos depósitos eólicos pode ser progressiva ou 
intensa por bordejarem as praias. E aborda-se ainda sobre a relevância da conservação desses geossítios costeiros nesse sistema.

\subsection{Referencial teórico}

Brilha (2005), descreve sobre os valores da geodiversidade, que são o intrínseco, cultural, estético, econômico, funcional, cientifico e didático. O valor contemplado no estudo será o funcional onde expõe a ideia de não ser aplicável à natureza, tendo em vista a sua conservação. É caracterizada ainda sobre duas perspectivas, a in situ, que faz referencia a geodiversidade partindo do pressuposto da apropriação do homem. E enquanto substrato, adquirindo relevância através do suporte para sustentação dos sistemas físicos e ecológicos na terra.

A utilização desse valor é em virtude do litoral de Almofala ser protegido por duas feições distintas as dunas frontais e os eolianitos localizados na faixa de praia, estando sujeitos a processos erosivos naturais. Para Hesp (2002) as dunas frontais consistem em cristas dunares arenosas vegetadas, estando sujeitas a eventos de alta energia. Para Carvalho (2009 apud Sayles 1931), os eolianitos são definidos como sendo rochas sedimentares formadas no momento da deposição pela ação do vento. Carvalho (2009) realizou estudos referentes aos eolianitos no litoral cearense, destacando a composição mineralogica e biogênica, esta ultima proveniente de sedimentos marinhos rasos, além da possibilidade de interpretação das condições paleoambientais do clima do litoral do Ceará que estas feições expressam.

Carvalho (2009) realiza os primeiros estudos sobre os eolianitos no litoral cearense, destacando a composição mineralogica da feição e a possibilidade de interpretação das condições paleoambientais, destacando o regime dos ventos no momento da formação da feição.

\section{Materiais e metodos}

A praia de Almofala localiza-se no litoral do município de Itarema $\left(2^{\circ} 55^{\prime} 13^{\prime \prime} \mathrm{S} / 39^{\circ} 54^{\prime} 54^{\prime \prime} \mathrm{W}\right)$ na setorização do litoral oeste do Estado do Ceará. Distando a $185 \mathrm{~km}$ da capital, Fortaleza. (IPECE, 2015). Seu acesso saindo de Fortaleza é pela BR-222, até Umirim e de lá, segue-se pela BR-402 até o distrito de Nascente, onde pega a CE-434 até Itarema.

A metodologia para o estudo consistiu em um inventário dessas feições utilizando o método $A d$ Hoc, que consiste na identificação e escolha de geossítios a serem selecionados de maneira isolada e com enfoque local (Rodrigues et. al. 2016). A proposta de inventariação é voltada para a representação da funcionalidade protetora das feições dunas frontais e eolianitos frente aos processos erosivos da praia de 
XVII Simpósio Brasileiro de Geografia Fisica Aplicada

I Congresso Nacional de Geografia Física

\section{OS DESAFIOS DA GEOGRAFIA FÍSICA NA FRONTEIRA DO CONHECIMENTO \\ Instituto de Geociências - Unicamp \\ Campinas - SP \\ 28 de Junho à 02 de Julho de 2017}

Almofala, sendo que essas feições por estarem expostas a eventos de alta energia consequentemente também estão vulneravéis ao processo de erosão natural.

Para realização dos objetivos traçados neste trabalho foi realizada uma visita de campo no mês de Setembro de 2016, onde os geossítios da geodiversidade litorânea foram mapeados com o auxilio de um receptor GPS (Garmim GPS60), foi realizado também um levantamento fotográfico para cada geossítio apontado ao longo da pesquisa. O campo foi realizado em período de preamar de sizígia.

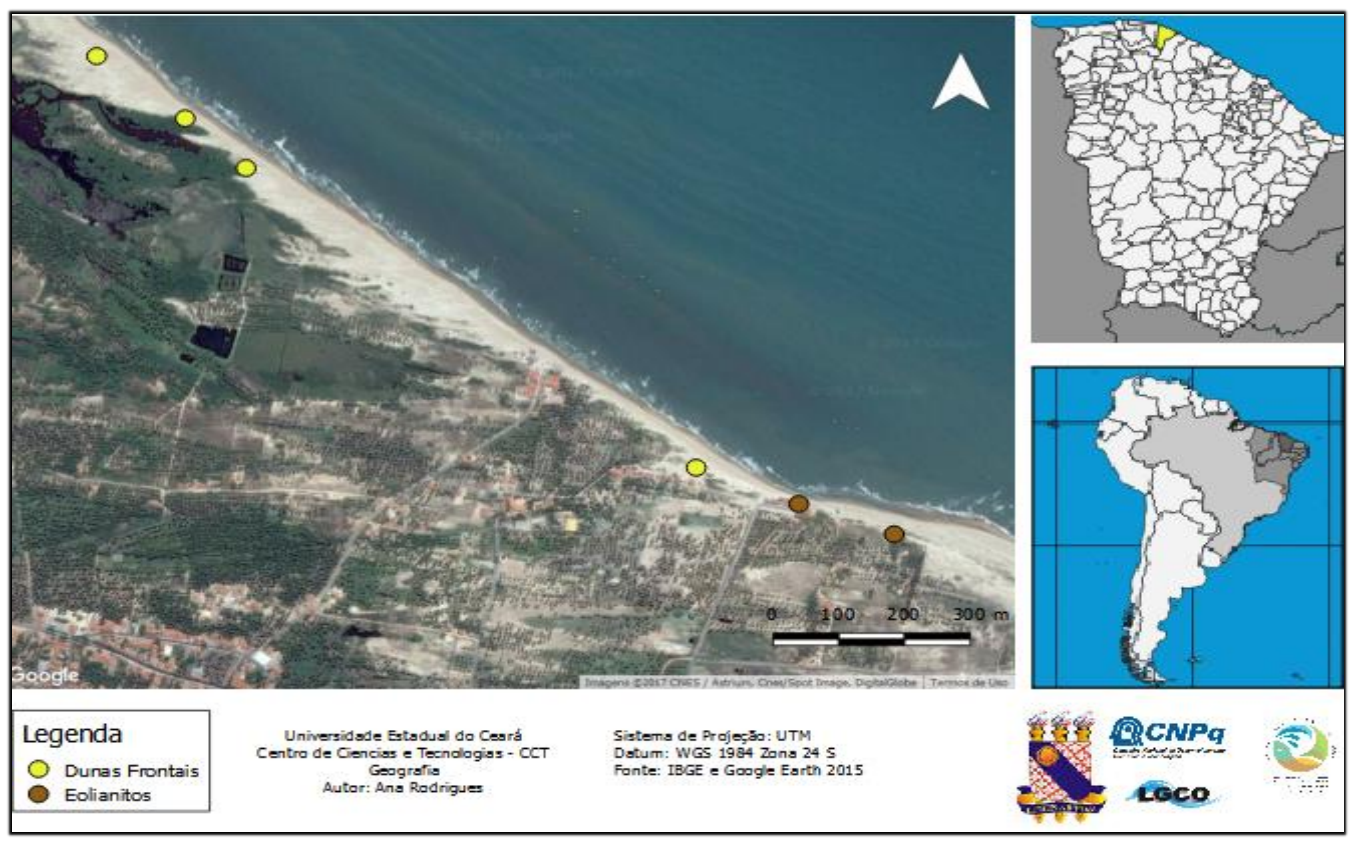

Figura 1: Mapa de localização da área e geossítios costeiros.

\section{Resultados e discussões}

\subsection{Inventário}

Na praia de Almofala foram identificadas duas feições que atuam como primeira linha de proteção do litoral contra os eventos de alta energia são elas, as dunas frontais e os eolianitos. Essas duas feições desempenham papéis fundamentais em áreas costeiras, como a proteção frente aos processos erosivos ocasionados pela dinâmica do próprio ambiente, mas também no equilibrio e suprimento sedimentar da praia. 
Dunas frontais: estas feições estão localizadas nos pontos A, B, C e D da área de estudos. Através dos registros fotográficos e observação empirica ficou preceptível o espraiamento e sobrelavagem frente a essas feições. No ponto A as dunas frontais apresentam-se vegetadas e com escarpamentos em direção ao mar, e são ainda sobrelavadas pela massa d' água, podendo ser inferido que esse subsistema além de ser retrabalhado pela ação eólica, também é influenciado pela ação hidráulica. (Figura 2 A). Nos pontos B, C e D é perceptível o espraiamento nessas feições ocasionados pela ação da maré. (Figura 2 B, C e D).

Eolianitos: estas feições localizam-se nos pontos E e F da área de estudos, estando dispostos na faixa de praia, em contato direto com o mar na maré alta, expondo em alguns trechos à deterioração proporcionada por esse agente hidrodinâmico, e um constante retrabalhamento do processo eólico. Através dos registros fotográficos percebeu-se a ocorrência de um solapamento frente a essas feições que fora no ponto E, onde se verificou também que o eolianito apresenta uma estratificação plana - paralela, com altura superior a $1,75 \mathrm{~m}$, percebe-se indícios de desmoronamentos na feição, ocasionados possivelmente pela ação da maré e vento. (Figura $2 \mathrm{E}$ ). No ponto $\mathrm{F}$ a feição encontra-se bem conservada, em virtude de um condicionante estrutural, um arenito de praia $(\mathrm{G})$, encontrar-se defronte a esse ponto. (Figura $2 \mathrm{~F} \mathrm{e} \mathrm{G}$ ).
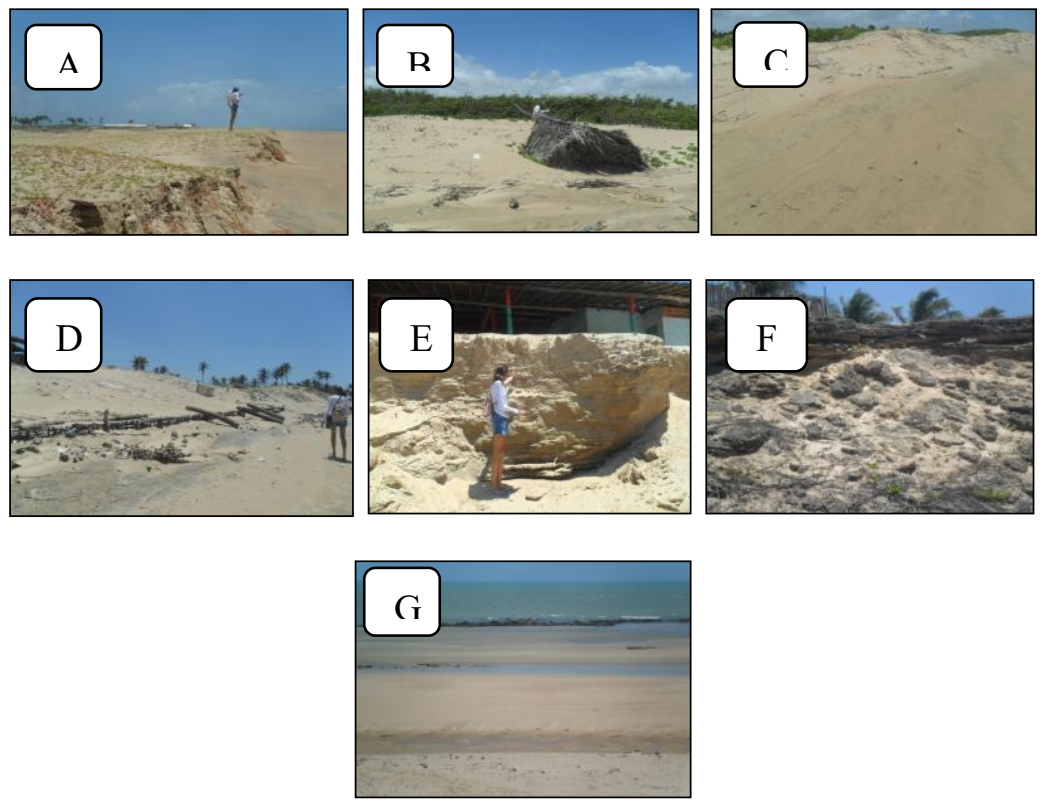

Figura 2: Pontos de identificação das dunas frontais. (A) duna frontal com vegetação exposta pela ação da maré. (B, $\mathrm{C}$ e D) perceptível alcance máximo da maré no referido dia. (E) eolianito solapado e com desmoronamento. (F) eolianito bem preservado e $(\mathrm{G})$ condicionante estrutural, protetor do eolianito, arenito de praia. 


\section{Conclusões}

Considerando a baixa ocupação da pós-praia e outras fontes de sedimentos, a erosão é causada por fatores naturais. $\mathrm{O}$ espraiamento é predominante na área nos pontos $\mathrm{B}, \mathrm{C}$ e $\mathrm{D}$, e a sobrelavagem é localizada de forma pontual principalmente no ponto $\mathrm{A}$, o solapamento no ponto $\mathrm{E}$, e no ponto $\mathrm{F}$ ocorre a proteção do eolianito por um fator estruturante o arenito de praia.

Ficou explicíto que os eolianitos apresentam uma maior resistência frente aos processos de erosão costeira, por apresentarem uma litologia mais rígida, sendo composto por areia e cimentação carbonática.

A conservação desses geossítios costeiros é necessária, pois é perceptível a representatividade protetora frente à alta dinâmica do litoral deixando assim exposta a vulnerabilidade natural desse ambiente.

\section{Agradecimentos}

Ao $\mathrm{CNPq}$ pela bolsa de Iniciação Científica disponibilizada a primeira autora. Ao apoio recebido pelo projeto Geodiversidades, interações e impactos socioambientais no sistema Praia-Plataforma da Costa Oeste do Estado do Ceará (PRONEX-CNPq-FUNCAP). Ao Laboratório de Geologia e Geomorfologia Costeira e Oceânica (LGCO).

\section{REFERÊNCIAS}

BRILHA, Jose. Patrimônio Geológico e Geoconservação: A conservação da natureza na sua vertente geológica. Braga: Palemage Editoes, 2005.

HESP, P. A. A gênese de cristas de praias e dunas frontais. Mercator - Revista de Geografia da UFC, 2002, vol. 01, número 02.

IPECE. Instituto de Pesquisa e Estratégia Econômica do Ceará. Perfil municipal básico de Itarema. 2015.

MEIRA, S. A. "Pedras que cantam": O Patrimônio Geológico do Parque Nacional de Jericoacoara, CEARÁ, BRASIL. Dissertação (Mestrado em Geografia) Universidade Estadual do Ceará. Fortaleza, 2016.

MORAIS. J.O. FREIRE G. S. S; PINHEIRO. L.S; SOUZA. M. J. N; CARVALHO. A. M. PESSOA. P. R.S; OLIVEIRA. S. H. M. Ceará. In: MUEHE. D. Erosão e Progradação do litoral brasileiro. Ministério do Meio Ambiente. 2006. P. 131 - 154.

RODRIGUES, A. A. S; MEIRA, S. A; MORAIS, J. O. Geodiversidade e Geossítios da Planície Costeira de Almofala, Município de Itarema, Ceará. Revista de Geociências do Nordeste, v. 2, nº 2, 38-47. 2016.

SOUSA. D.C; NASCIMENTO. M.A.L. Geoturismo no litoral de Icapuí/CE (NE do Brasil): uma alternativa de divulgação do patrimônio geológico. Revista de Geologia, v. 20, nº 2, 279-287. 2007.

SOUZA. C. R. G. A Erosão Costeira e os Desafios da Gestão Costeira no Brasil. Revista da Gestão Costeira Integrada, 9(1):17-37 (2009). 